\title{
Anaesthetic management for a Liver Transplant in a patient with Aagenaes Syndrome
}

Germanova L. ${ }^{1}$, Neves S. ${ }^{1}$, Oliveira D. ${ }^{1}$, Ralha T 1 ., Czajkowska K ${ }^{1}$. 1-Coimbra Hospital and Universitary Centre, Department of Anaesthesiology, Coimbra, Portugal.

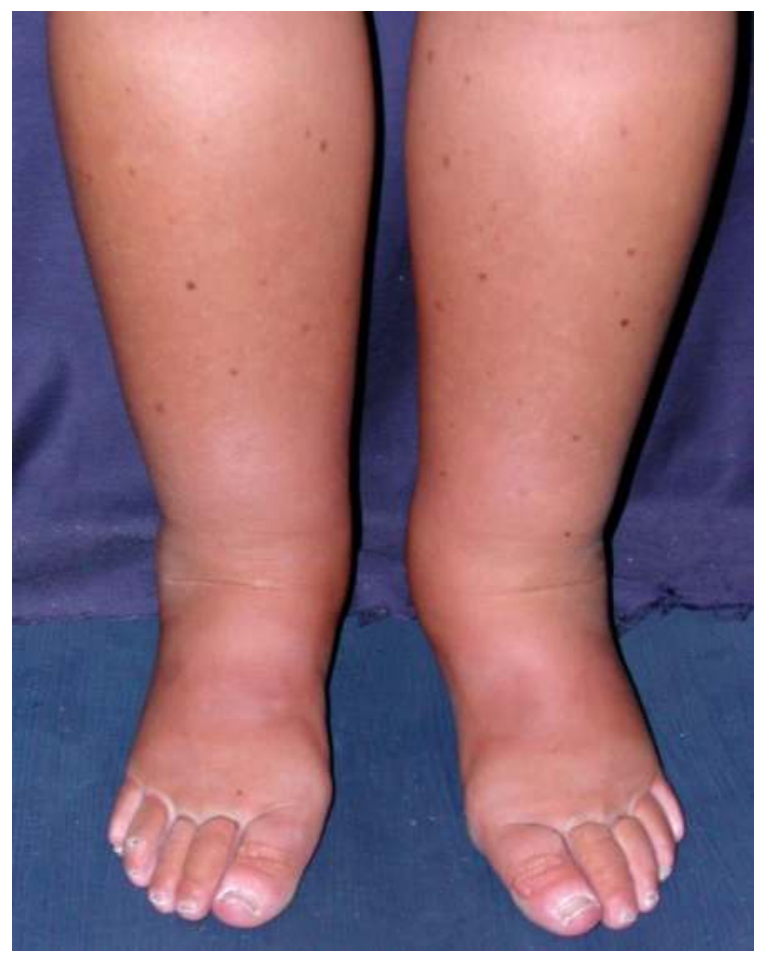

\section{Background:}

Aagenaes Syndrome (AS) is a clinical condition characterized by cholestasis and lymphedema, and is autosomal recessive inherited. It's a progressive disorder that can lead to end-stage liver disease and to hepatopulmonary syndrome (HPS).

The HPS is defined by the combination of intrapulmonary vascular dilatation and hypoxemia in patients with chronic liver disease. Liver transplant( LT) is described as the only effective treatment for HPS.

\section{Case report:}

We present a case of a 14 year-old boy with lymphedema and cholestasis with probable diagnosis of AS, scheduled for LT. He presented in the preoperative period with severe hypoxemia (paO2 of $44 \mathrm{mmHg}$ ), polycythaemia $(19 \mathrm{~g} / \mathrm{dL}$ ) and hematocrit 57\%. There was mild hepatic dysfunction. We performed a balanced general anaesthesia. Patient was ventilated, no PEEP was added, $\mathrm{FiO} 2$ around 0.45 and $\mathrm{paO} 2$ above $100 \mathrm{mmHg}$ during the procedure. The vital signs remained stable with noradrenaline and dopamine in a maximum dose of $0,4 \mu \mathrm{gg} / \mathrm{Kg} / \mathrm{min}$ and $7,5 \mu \mathrm{g} / \mathrm{Kg} / \mathrm{min}$, respectively. . No blood products were infused. There were no adverse events during de surgery. After a 10 hours procedure, the patient was transferred to the ICU ventilated.

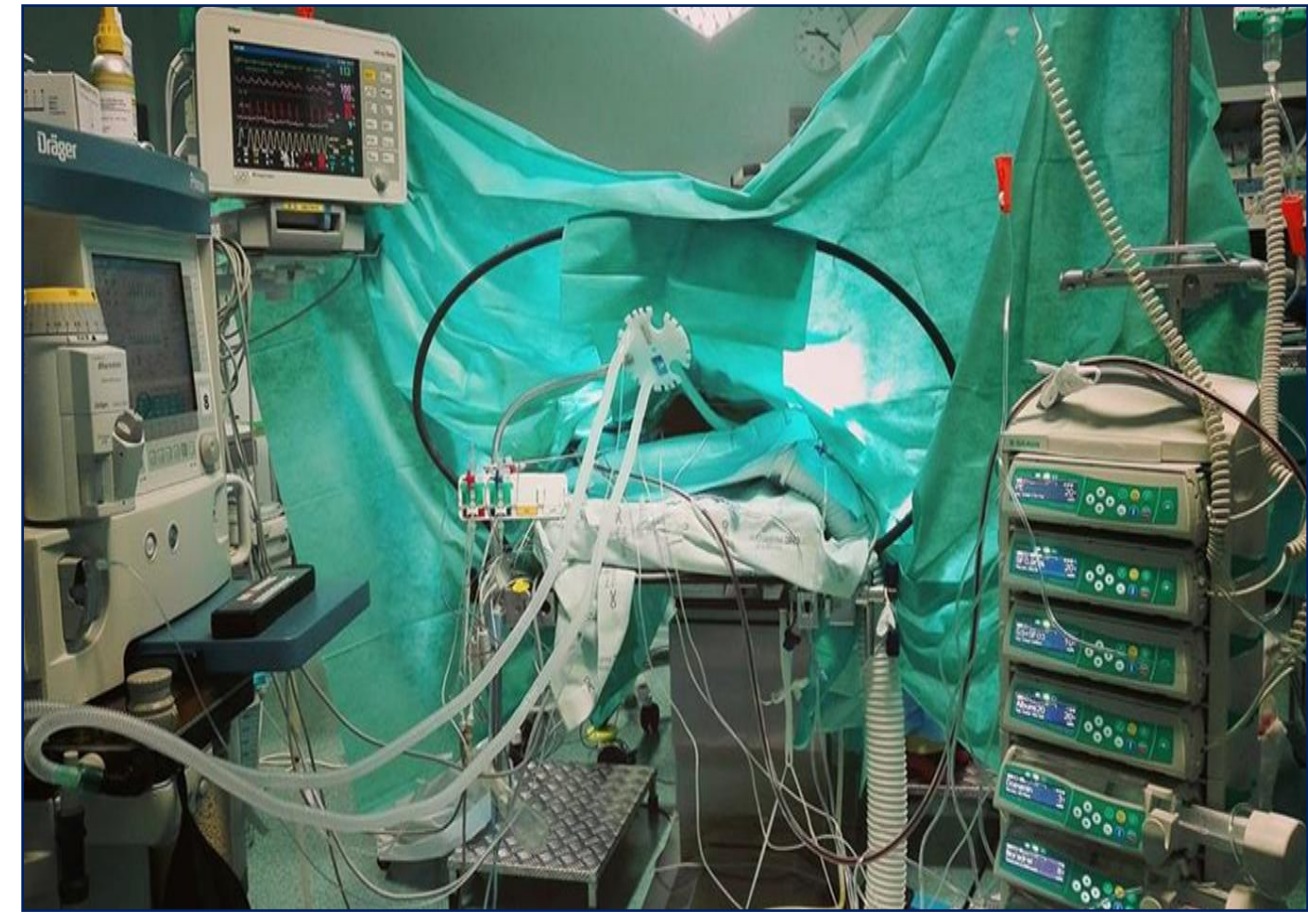

\section{Discussion:}

HPS originates from the development of intrapulmonary vascular dilation and usually an intrapulmonary right-to-left shunt develops, with hypoxia, dyspnoea, and polycythaemia. This makes LT a riskier procedure and a challenge to the anaesthesiologist. Despite the risk, the only definitive treatment of HPS is LT. Several studies have shown that HPS is cured or significantly improved in more than $85 \%$ cases within 6-12 months after LT. Hypoxic pulmonary vasoconstriction (HPV) should be maintained to avoid hypoxemia worsening. Despite the use of general balanced anaesthesia, considered to increase hypoxemia by inhibiting the HPV in higher degree when compared to intravenous agents, usually this effect do not persist after one hour. There was also a big concern about the polycythaemia and the augmented risk of anastomotic vessels thrombosis during reperfusion phase. In this case, there were no thrombotic complications even with $\mathrm{Hg}$ levels around $17 \mathrm{~g} / \mathrm{L}$.

\footnotetext{
1.Aagenaes O, Van Der Hagen CB, Refsum S. Hereditary recurrent intrahepatic cholestasis from birth. Arch Dis Child 1968;43:646-57;

2.Aldenkortt F, Aldenkortt M, Caviezel L, Waeber J, Weber A, Schiffer E.2014. Portopulmonary hypertension and hepatopulmonary syndrome. World J Gastroenterol. 20(25):8072-8081;
}

3.Mandell M, Masahiko T. Pulmonary complications of liver disease. Liver anesthesiology and critical care medicine. 1st edition. New York: Springer; 2012. p. 255-64. 